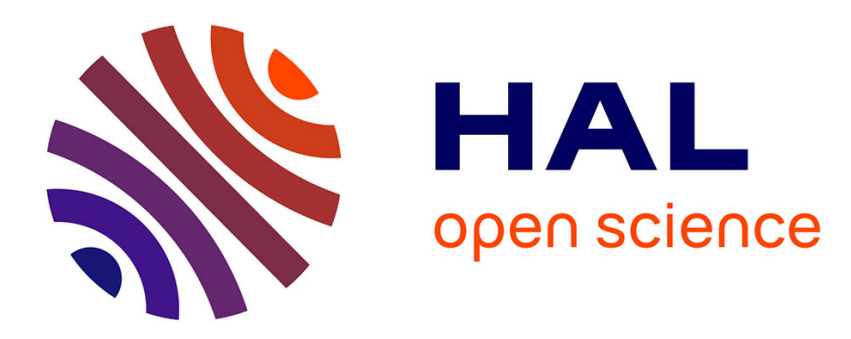

\title{
Transient surface grating technique for thermal diffusivity measurement
}

\author{
M. Alam, R. Imhof, B. Zhang
}

\section{To cite this version:}

M. Alam, R. Imhof, B. Zhang. Transient surface grating technique for thermal diffusivity measurement. Journal de Physique IV Proceedings, 1994, 04 (C7), pp.C7-299-C7-302. 10.1051/jp4:1994771. jpa-00253300

\section{HAL Id: jpa-00253300 https://hal.science/jpa-00253300}

Submitted on 1 Jan 1994

HAL is a multi-disciplinary open access archive for the deposit and dissemination of scientific research documents, whether they are published or not. The documents may come from teaching and research institutions in France or abroad, or from public or private research centers.
L'archive ouverte pluridisciplinaire HAL, est destinée au dépôt et à la diffusion de documents scientifiques de niveau recherche, publiés ou non, émanant des établissements d'enseignement et de recherche français ou étrangers, des laboratoires publics ou privés. 


\title{
Transient surface grating technique for thermal diffusivity measurement
}

\author{
M. Alam, R.E. Imhof and B. Zhang \\ Department of Physics and Applied Physics, Strathclyde University, Glasgow G4 ONG, U.K.
}

\begin{abstract}
A new transient surface grating technique specifically designed for measuring thermal diffusivities of condensed materials is described. Its capabilities are illustrated with measurements of the thermal diffusivities of copper and glass.
\end{abstract}

\section{INTRODUCTION}

Transient grating techniques have been used to study material properties including thermal, acoustic, hydrodynamic and electronic parameters, since the mid-1970s [eg 1]. Until recently however, such experiments used transmission geometries, which restricted their application to transparent samples of high optical quality. The innovation of surface reflective sensing from essentially opaque samples [2-4] obviates the need for high optical quality and allows measurements to be made without access to both sides of the sample, thus widening very considerably the range of materials and sample geometries that can be studied. The surface specificity of this approach [5] makes the technique suitable for studying near-surface phenomena and thin films, thus addressing important industrial material evaluation needs.

The transient surface grating (TSG) technique reported here uses two pulsed, intersecting, coherent pump beams to produce interference bands of low and high irradiance on the surface of the sample. This causes a diffraction grating pattern of thermal expansion and modulated reflectance to be produced, which is detected by measuring the intensity of a diffracted probe beam of different wavelength. The work presented here concentrates on thermal diffusivity measurement in homogeneous, thermally thick materials. We also show that measurements can be made on heterogeneous materials, thus opening up a much wider range of non-destructive testing possibilities than first envisaged.

\section{INSTRUMENTATION}

A schematic diagram of the instrument is shown in Figure 1. It uses a Spectron Q-switched Nd:YAG pump laser, with pulses of $\approx 15 \mathrm{~ns}$ duration, $\approx 3 \mathrm{~Hz}$ repetition frequency and single transverse mode output of either second $(532 \mathrm{~nm})$ or fourth $(266 \mathrm{~nm})$ harmonic wavelengths. The beam is split and recombined onto the sample surface using a Mach-Zehnder interferometer, consisting of two beam splitters, BS1 and BS2, and two mirrors, M1 and M2. An apertured pump beam of $\approx 6 \mathrm{~mm}$ diameter is used without focussing, in order to minimise the risk of surface damage. The use of beam splitter BS2 for recombining the excitation beams, in place of conventionally used mirrors or prisms, allows very small beam inclinations to be produced in a compact optical geometry. The grating spacing can be varied between $5 \mu \mathrm{m}$ and $100 \mu \mathrm{m}$ by precisely controlled adjustments of the positions and inclinations of mirrors M1 and M2. The transient grating is probed by diffraction of a $\mathrm{cw}$ HeNe laser beam of $\approx 3 \mathrm{~mm}$ diameter and 
$633 \mathrm{~nm}$ wavelength. The area probed is wholly within the area pumped by the Nd:YAG laser, in order to reduce measurement errors arising from surface temperature gradients other than those associated with the transient grating itself. Its expanded diameter of $\approx 3 \mathrm{~mm}$ gives a high sensitivity and angular resolution by diffracting from as large a number of grating lines as practical. Diffracted light is collected by means of a telescope of $30 \mathrm{~mm}$ focal length, fitted with $633 \mathrm{~nm}$ interference filter, to reject excitation radiation and ambient light, and focused into a $200 \mu \mathrm{m}$ diameter optical fibre of $8 \mathrm{~m}$ length. This arrangement provides excellent rejection of light scattered from less than optically perfect sample surfaces. The separation of the photomultiplier from the Nd:YAG laser also helps to reduce signal distortion due to electromagnetic interference, whilst minimising the weight carried by the precision radius arm, designed to give rapid alignment of the telescope with the diffracted probe beam. Transient signals are captured in a digital

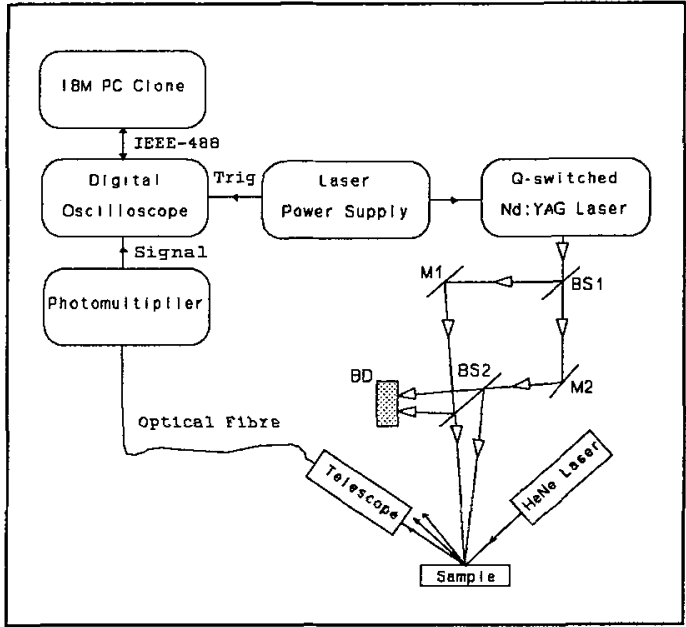

Figure 1 Schematic diagram of the TSG apparatus. M1 and $\mathrm{M} 2$ are mirrors, BS1 and BS2 beam splitters and $\mathrm{BD}$ a beam dump. oscilloscope of $1 \mathrm{GHz}$ maximum sampling rate (HP 54510A), interfaced to a PC via a high speed IEEE-488 link, for real time signal averaging, storage, analysis and display.

\section{RESULTS}

Thermal diffusivity measurements were performed at room temperature by observing transient grating decays over a range of grating spacings. Sample surfaces were prepared to reasonably bright finish, which was nevertheless short of optical quality. Grating spacings were measured using microscopic examination of sacrificial samples of floppy disk, onto which grating patterns had been ablated at high excitation fluence.

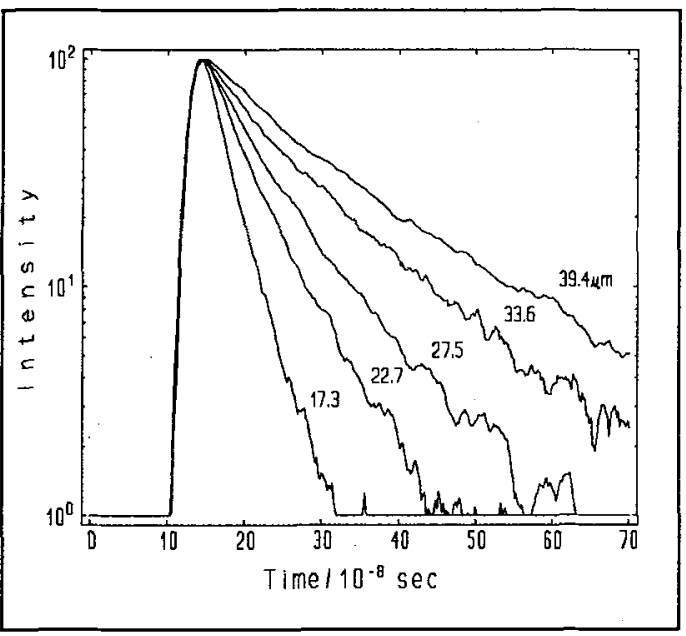

Figure 2 TSG decay curves for copper at a range of grating spacings, averaged over 256 excitation pulses.

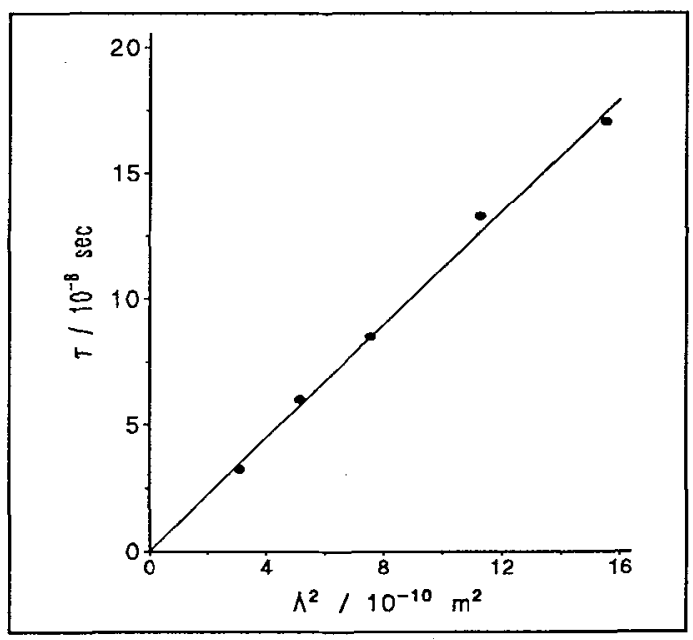

Figure 3 Analysis of the data of Figure 2 using the single exponential decay model of Eqs.(1-2). 


\subsection{Copper}

A pump wavelength of $532 \mathrm{~nm}$ was used on a high purity multi-crystalline copper disk of $10 \mathrm{~mm}$ diameter and $5 \mathrm{~mm}$ thickness, supplied by Goodfellow Metals Ltd. The observed decay curves, illustrated in Figure 2, fit well to an exponential model [6], derived assuming that probe beam diffraction occurs mainly from surface undulations caused by thermal expansion perpendicular to the sample surface,

$$
I(t)=\xi\left(\frac{a E_{0}}{\lambda \rho C}\right)^{2} e^{-\frac{t}{\tau}} \quad \text { with } \quad \tau=\frac{\Lambda^{2}}{8 \pi^{2} D}
$$

where $I$ is the first order diffracted beam intensity, $\zeta$ an instrumental sensitivity factor, $a$ the linear thermal expansion coefficient, $\boldsymbol{E}_{\boldsymbol{0}}$ the pump energy absorbed, $\lambda$ the probe wavelength, $\boldsymbol{\rho}$ the density and $\boldsymbol{C}$ the specific heat. The decay time $\tau$ is related to the thermal diffusivity $D$ and grating spacing $\Lambda$. Figure 3 illustrates the precision of measurement achieved and provides a further test of the model through the direct proportionality between the fitted decay times and the square of the grating spacing. From this analysis, $D_{C u}=(1.13 \pm 0.02) \times 10^{-4} \mathrm{~m}^{2} \mathrm{~s}^{-1}$ at $18^{\circ} \mathrm{C}$, well within the wide range of accepted values [7].

\subsection{Glass}

TSG decay curves of a specimen of float glass of $\approx 6 \mathrm{~mm}$ thickness, measured using a pump wavelength of $266 \mathrm{~nm}$, are shown in Figure 4 . The decays from $\approx 200 \mathrm{~ns}$ after the peak were found to fit well to the exponential model. The dependence of fitted decay times on the square of the grating spacing is shown in Figure 5. In contrast to copper and other thermally thick metal samples studied, the extrapolated best-fit straight line of Figure 5 does not pass through the origin in this case. This is not surprising, since the float surface of float glass is known to be highly inhomogeneous, because of near-surface impurities related to tin and its compounds [8]. Its gradient, evaluated according to Eq.(1) and [4], implies an effective thermal diffusivity of $9.0 \times 10^{-7} \mathrm{~m}^{2} \mathrm{~s}^{-1}$, which is entirely plausible, though somewhat higher than that of common glasses (eg $D \approx 5.7 \times 10^{-7} \mathrm{~m}^{2} \mathrm{~s}^{-1}$ for Flint glass and $D \approx 3.8 \times 10^{-7} \mathrm{~m}^{2} \mathrm{~s}^{-1}$ for Crown Glass). Another feature of these measurements is the rapidly decaying initial peak on the decay curves shown in Figure 6. We think these are caused by fluorescence of the glass, since they persist when one of the pump beams is blocked.

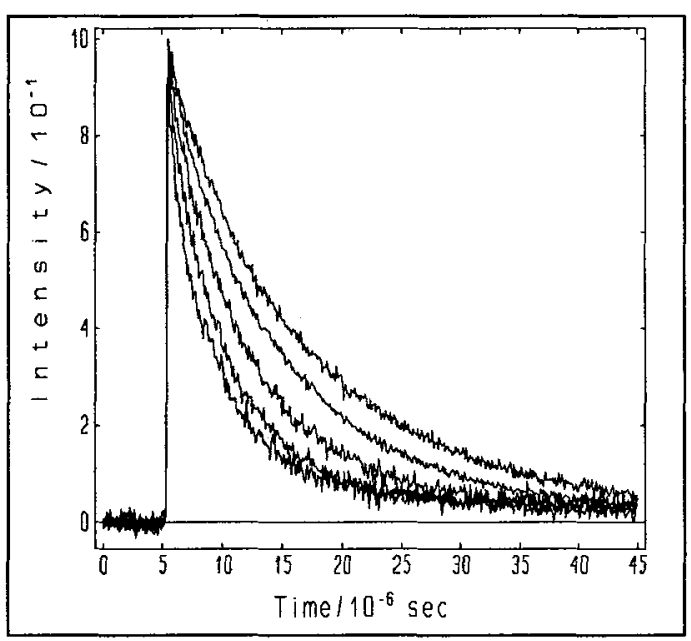

Figure 4 TSG decay curves for the float surface of a float glass. From top to bottom, $\Lambda=26.0,22.6$, $18.7,15.8$ and $14.6 \mu \mathrm{m}$.

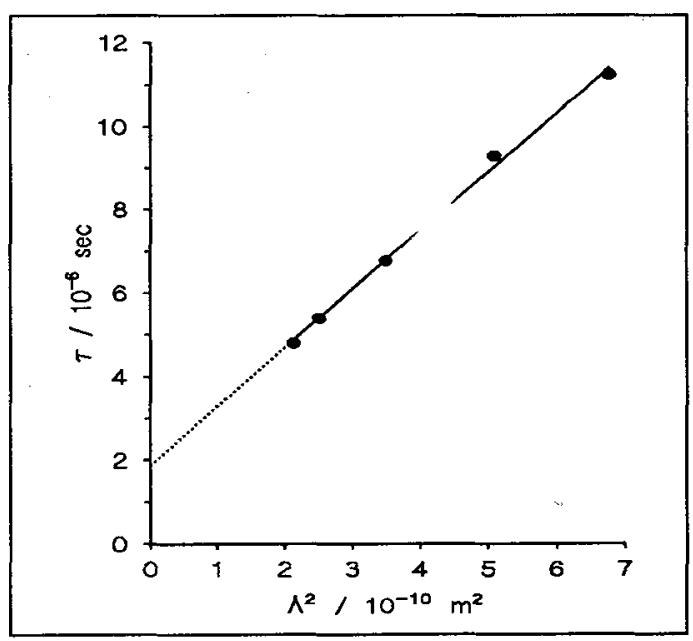

Figure 5 Analysis of the data of Figure 4 using the single exponential decay model of Eq.(1). 


\subsection{Thermo-acoustic Effects}

Observations on a wide range of materials and measurement conditions showed that the pump energy was predominantly converted to heat, with little evidence of the coherent surface acoustic waves observed by others (eg [3]). This suppression of acoustic modes within the samples was attributed to the relatively wide pulse $(\approx 15 \mathrm{~ns})$ of the pump laser, the large grating spacing and low excitation fluence used in this work. What we observed with some samples was an acoustic effect not previously reported, namely the excitation of coherent acoustical waves in the air above the probed surface, manifested as oscillations superimposed on the thermal decays [6]. The two decay curves of Figure 6 with the largest grating spacings show some evidence of this.

\section{CONCLUSIONS}

The results illustrate the potential of the technique for precision thermal diffusivity measurement. Work is currently in progress to study applications in semiconductors and thin films, to extend the

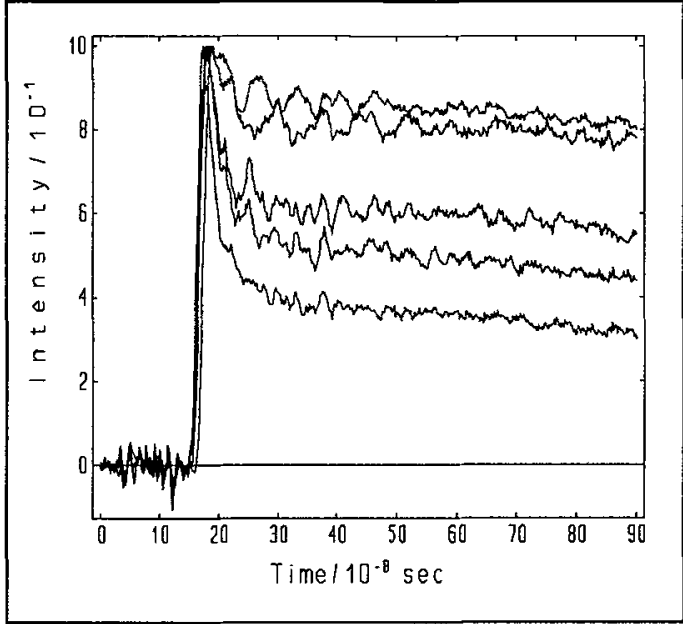

Figure 6 Magnified initial decays of the impulse response curves of Figure 4, showing rapidly decaying components which become more pronounced with decreasing grating spacing. From top to bottom, $\Lambda=22.6,26.0,18.7,15.8$ and $14.6 \mu \mathrm{m}$. usefulness of the technique to other areas of NDE.

\section{Acknowledgement}

We thank the SERC and NPL for research support, the Ministry of Education, Pakistan for a COT Scholarship (M.Alam) and John Reevie for his invaluable technical assistance.

\section{References}

[1] Selzer P.M. Laser-Induced Dynamic Gratings (Springer Series in Optical Sciences 50, Editors: Eichler H.J. Günter P. and Pohl D.W. Springer Verlag, Berlin, Heidelberg 1986).

[2] Imhof R.E. and Birch D.J.S. British Patent Application No. 87.24248:(1987). Full Patent No. 2224835:(1992).

[3] Harata A. Nishimura H. and Sawada T. Appl.Phys.Lett. 57(1990) 132-134.

[4] Jauregui J. and Matthias E. Appl. Phys. A54(1992) 35-39.

[5] Pennigton D.M. and Harris C.B. IEEE J.Quant.Electron. 28(1992) 2523-2534.

[6] Alam M. Imhof R.E. and Zhang B. to appear in J.Phys.D: Appl.Phys.

[7] Touloukian Y.S. and Buyco E.H. Thermophysical Properties of Matter-Thermal Diffusivity (TPRC Data Series, New York: Plenum 1973) 10 pp.51-61.

[8] Imhof R.E. Birch D.J.S. Bindra R.M.S. Willson P.H. Locke J. and Sanger D.J. J.Phys.D: Appl.Phys. 24(1991) 2067-2071. 